\title{
PENDIDIKAN KELUARGA DI ERA MERDEKA BELAJAR
}

Oleh:

\author{
${ }^{1}$ Firda Rizka Rachma Wahdani
}

Firda.wahdani@gmail.com

${ }^{2}$ Hamam Burhanuddin

Institut Agama Islam Sunan Giri Bojonegoro

hmmudin@gmail.com

\begin{abstract}
Family is most important places in instilling education for children, the family will create a desirable generation, parents become one of the important factors in education, inattention of parents to children will cause children to become neglected in their education, children deserve the love from parents and full attention. In 2045 Indonesia will get a demographic bonus where the productive age is more than the non-productive, this will be very closely related to the current education, especially education in the family environment needs to be prepared carefully related to strategy and implementation. By applying the concept of free learning in the family environment as an effort to help children in solving learning difficulties, correcting bad behavior and habits, as well as providing reinforcement in the intellectual and spiritual realms. it is expected that education in Indonesia can become more advanced, of quality, and can give birth to a golden generation that is resilient in facing various challenges in the future.
\end{abstract}

Keynote: Family Education, Merdeka Belajar.

\section{A. PENDAHULUAN}

Indonesia di tahun 2045 akan mencapai 100 tahun usia kemerdekaan. Di usia satu abad itu, Indonesia harus mampu mengatasi berbagai macam permasalahan. sehingga membutuhkan kerjasama dari berbagai pihak, baik dari instansi pendidikan, ataupun orang tua. Jadi, pendidikan dalam keluarga menjadi sangat urgen dan dibutuhkan dalam rangka memperbaiki kualitas pembelajaran seorang peserta didik, karena pendidikan bukan hanya digerakkan oleh pemerintah ataupun kurikulum belaka.

\footnotetext{
${ }^{1}$ Mahasiswa Prodi Pendidikan Agama Islam Fakultas Tarbiyah IAI Sunan Giri Bojonegoro

2 Dosen IAI Sunan Giri Bojonegoro
} 
Pendidikan yang berkualitas dapat diperoleh dari proses pembelajaran yang bermutu. Pembelajaran yang bermutu merupakan pembelajaran yang memperhatikan aspek kognitif (otak), afektif (sikap), dan psikomotorik (perilaku) secara seimbang, karena pendidikan bertugas untuk mencetak generasi yang unggul dengan intelegensi spiritual dan intelegensi emosional yang baik. Hal ini sejalan dengan amanat pendidikan dalam UU No. 20 Tahun 2003 tentang pendidikan nasional yang fungsi utamanya adalah untuk mengembangkan kemampuan dan mencetak karakter yang unggul, serta bangsa yang bermartabat untuk mencerdaskan kehidupan berbangsa. ${ }^{3}$

Berdasarkan fungsi pendidikan diatas, maka untuk mewujudkannya pemerintah Indonesia mengeluarkan kebijakan sistem pendidikan yang baru. Program tersebut akrab dikenal dengan istilah 'Merdeka Belajar'. ${ }^{4}$ Dengan memahami konsep merdeka belajar yang didukung dengan adanya pendidikan keluarga, diharapkan pendidikan di Indonesia dapat menjadi lebih maju, berkualitas, dan dapat melahirkan generasi emas yang tangguh dalam mengahadapi berbagai tantangan di masa depan.

\section{B. PEMBAHASAN}

\section{A. Konsep Pendidikan Keluarga}

Menurut Padil keluarga merupakan kelompok terdiri dari dua orang atau lebih dan memiliki hubungan darah yang terikat tali pernikahan atau

\footnotetext{
${ }^{3}$ Undang Undang Sistem pendidikan Nasional Tahun 2003.

${ }^{4}$ Program tersebut mengutamakan prinsip kebebasan pada guru dan peserta didik. Menurut Siti Mustaghfiroh dalam studi penelitiannya yang berjudul "Konsep Merdeka Belajar Perspektif Aliran Progresivisme John Dewey", mengungkapkan bahwa terdapat kesejajaran antara konsep Merdeka Belajar dengan konsep pendidikan menurut aliran filsafat Progresivisme John Dewey. Kedua konsep tersebut samasama menekankan adanya kemerdekaan dan keleluasaan lembaga pendidikan dalam mengembangkan secara maksimal potensi yang dimiliki oleh anak secara alamiah, karena setiap anak memiliki kemampuan dan potensi yang beragam. Jika dirumuskan kedua konsep tersebut sama-sama mengandung makna yang senada, yaitu peserta didik harus bebas dan berkembang secara natural; Pengalaman langsung adalah rangsangan terbaik dalam pembelajaran; Guru harus bisa memandu dan menjadi fasilitator yang baik. Lembaga pendidikan harus menjadi laboratorium pendidikan untuk perubahan peserta didik. Disisi lain, aktivitas di lembaga pendidikan dan di rumah harus dapat dikooperasikan. Siti Mustaghfiroh, Konsep "Merdeka Belajar" Perspektif Aliran Progresivisme John Dewey. Jurnal Studi Guru dan Pembelajaran, Vol. 3, No. 1, Maret.2020. hal. 145.
} 
pengadopsian anak. ${ }^{5}$ sementara itu menurut Djamarah keluarga merupakan bentuk kelembagaan yang terjalin karena adanya sebuah ikatan pernikahan dengan tujuan dan cita-cita untuk menjadikan keluarga bahagia dan sejahtera lahir batin. ${ }^{6}$ Sementara itu Yusuf memberikan penjelasan tentang pendidikan yang diberikan keluarga merupakan bagian dari usaha pembimbingan dan atau pembelajaran yang diberikan terhadap anggota keluarga suatu keturunan dalam rumah, yang terdiri dari bapak, ibu, anak. ${ }^{7}$

Dari penjelasan di atas dapat di tarik pemahaman bahwa keluarga merupakan sekelompok orang yang terikat oleh tali pernikahan baik darah dengan tujuan memberikan bimbingan dan pembelajaran kepada keturanannya terutama kepada anak.

\section{Tujuan Pendidikan dalam Keluarga}

Tujuan pendidikan keluarga dalam perspektif pendidikan Islam ialah pertama, menanamkan keimanan dan ketaatan kepada Allah, melalui pendidikan Islam anak dilatih untuk selalu dekat dan merasa dipantau oleh Allah atas kesadaran individu. Kedua, untuk membentuk karakter dan akhlak yang mulia, melalui penerapan nilai-nilai pendidikan Islam atau keyakinan sebagaimana yang tercantum dalam QS. Luqman ayat 12-19, yaitu agar selalu anak menjadi manusia yang bersyukur kepada Allah, apalagi mempersekutukan Allah, anak berbakti kepada kepada kedua orang tua, melakukan kewajiban shalat, memiliki sikap sederhana, tidak sombong dalam berjalan, dan memelankan suaranya.

Sedangkan tujuan secara jasmani pendidikan anak dalam keluarga ialah mencetak anak agar memiliki potensi secara individu, sosial, dan professional, kita perlu takut dan khawatir jika keturuan keluarga dalam kondisi yang lemah pada segala aspek, oleh karena sejak dini harus

\footnotetext{
120.

5 Muhammad Padil dan Triyo Suprayitno, Sosiologi Pendidikan, (Yogyakarta: Sukses Offset, 2007), hal. 6 Syaiful Bahri Djamarah, Pola Asuh Orang Tua dan Komunikasi dalam Keluarga, (Jakarta: Rineka Cipta, 2014), hal. 18.

7 M. Yusuf, Tafsir Tarbawi, ..., hal. 150.
} 
menyiapkan keluarga yang kuat. sesuai dengan firman Allah QS. An-Nisa' ayat $9 .^{8}$

kuat secara individu dimana anak memiliki kemampuan pada aspek kognitif (otak), afektif (sikap), dan psikomotrik (perilaku). Arti kuat secara sosial ketika anak mampu bersosialisasi dalam kehidupan sosial masyarakat. Sementara kuat pada aspek profesional anak mampu hidup mandiri untuk mengembangkan kemampuan yang dimiliki sehingga dapat diperdigunakan memenuhi kebutuhan secara mandiri. ${ }^{9}$

\section{Proses Pendidikan di Lingkungan Keluarga}

Pendidikan keluarga dapat dikelompokkan menjadi tiga :

a) Keterampilan menguasai diri. mendidik anak untuk menguasai diri sendiri bisa dimulai saat orang tua memberikan pelatihan kepada anak dengan cara menjaga kebersihan diri sendiri, latihan ini menjadi latihan pada diri anak. Dilanjutkan pengembangan fisik kepada penguasaan diri anak secara emosional. Orang tua dalam hal ini dituntut untuk memberikan intruksi atau secara demokratis.

b) Pendidikan nilai, menanamkan pendidikan nilai pada anak bersamaan dengan keterampilan menguasai diri, Misalkan ketika anak memasuki usia 6 tahun saat bermain menggunakan mainan bersama dengan teman-temannya, orang tua dapat memberikan arahan supaya meminjamkan mainan kepada teman-temannya.

c) Peranan sosial, setelah anak memunculkan kesadaran diri dan mampu membedakan perannya dengan orang lain, maka anak dilatih untuk memiliki peran yang sesuai dengan gambaran dirinya. Hal ini bisa dilatih melalui lingkungan keluarga, teman sebaya, lingkungan sekolah. ${ }^{10}$

\footnotetext{
8 Jalal al-Din Mahalliy \& Jalal al-Din as-Suyuthi, Terjemah Tafsir al-Jalalain jil.3, terj.Bahrun, (Bandung : Sinar Baru, 1990) hlm. 1745-1749

${ }^{9}$ Helmawati, Pendidikan Keluarga: Teoritis dan Praktis, (Bandung : PT Remaja Rosdakarya, 2014), hIm. 51

${ }^{10}$ MohammadPadil dan Triyo Suprayitno, Sosiologi Pendidikan, hal. 127-28.
} 


\section{B. Konsep Merdeka Belajar}

Nadiem Anwar Makariem telah menetapkan beberapa hal terkait dengan pendidikan di Indonesia sebagai upaya menghasilkan sumber daya manusia yang bermutu dan berkualitas. Program tersebut dikenal dengan istilah "Merdeka Belajar". Merdeka Belajar adalah sebuah sistem pendidikan yang didalamnya mengutamakan kebebasan, baik pada guru maupun peserta didik. Maknanya sistem pembelajaran akan berganti, dari yang awalnya tatap muka di dalam kelas akan menjadi di luar kelas (out door). Suasana pembelajaran akan berjalan lebih rileks, karena siswa dapat mendiskusikan materi bersama guru, belajar dengan outing class, siswa tidak hanya sekedar mendengarkan penjelasan materi guru, pembentukan karakter siswa yang berani, mandiri, berakhlak, kompetisi, dan tidak hanya mengandalkan sistem ranking. Pada kenyataannya setiap anak memiliki bakat dan kecerdasan yang berbeda-beda sesuai dengan bakat dan minatnya. ${ }^{11}$

Terdapat empat poin yang terkandung dalam kebijakan Merdeka Belajar. Pertama, Ujian Nasional (UN) yang akan diganti dalam bentuk lain seperti asesmen kompetensi minimum dan survei karakter. Kedua, sekolah akan diberikan kewenangan untuk menyelenggarakan Ujian Sekolah Berstandar Nasional (USBN), sekolah diberikan hak priogatif dalam menentukan penilaian, seperti portofolio, tugas proyek, karya tulis, atau bentuk penugasan lain. Ketiga, Rencana Pelaksanaan Pembelajaran (RPP) disederhanakan menjadi satu lembar, sehingga guru dapat lebih fokus dalam membimbing dan mamantau perkembangan belajar pada siswa. Keempat, penerimaan peserta didik baru menggunakan sistem zonasi yang diperluas. ${ }^{12}$.

Kualitas pendidikan hendaknya selalu meningkat pada setiap tahunnya. Dalam mewujudkan kualitas pendidikan yang lebih maju, maka sudah seharusnya penyelenggaraan pendidikan bukan hanya menjadi tanggungjawab

\footnotetext{
${ }^{11}$ Siti Mustaghfiroh, Konsep "Merdeka Belajar" Perspektif Aliran Progresivisme John Dewey, hlm. 146.

12 Nanik Nurhayati,Makalah disampaikan pada Kuliah Tamu di IAI Sunan Giri Bojonegoro 07 Maret 2020.
} 
pendidik (guru) di sekolah, tetapi keluarga juga harus berperan dalam penyelenggaraan pendidikan di rumah. Hal ini bertujuan untuk membentuk sinergi yang baik.

Kemendikbud menyatakan perlu adanya kerjasama yang sinergis antara program pendidikan yang dilakukan dengan lingkungan keluarga. Dalam hal ini yang menjadi pedoman adalah Tri Sentra Pendidikan yang diprakarsai oleh Ki Hajar Dewantara. Tri Sentra Pendidikan menuntut adanya keselarasan pendidikan pada satuan pendidikan, keluarga, dan masyarakat.

Keluarga merupakan salah satu pilar yang dapat mendukung berhasilnya program Merdeka Belajar. Sebab pendidikan yang penting dan paling utama adalah dimulai dari keluarga. Sebagaimana hail penelitian yang dihasilkan oleh Hasan Baharun yang berjudul "Pendidikan Anak Dalam Keluarga: Telaah Epistemologi". Hasil dari penelitian tersebut menyatakan bahwa peran aktif keluarga (orang tua) di sekolah harus prioritaskan. Pendidikan dalam keluarga hendaknya berlandaskan pada asas kebebasan, pendidikan seharusnya memberi kebebasan sepenuhnya kepada anak untuk melakukan proses pembelajaran yang kreatif dan inovatif, tanpa ada pemaksaan dari kedua orang tuanya. Tugas orang tua adalah sebagai pengendali (controller) bagi perkembangan anak. Memaksakan perkembangan dan pertumbuhan anak dapat menyebabkan anak memiliki mental yang rendah dan memiliki sikap kurang percaya diri. Maka, pendidikan dalam keluarga orang tua sebaiknya memberi ruang bebas kepada anak, supaya anak dapat mengembangkan potensi pribadi tanpa tekanan dari orang tua. Pendidikan dalam keluarga sebaiknya menggunakan prinsip yang tepat, artinya orang tua harus paham betul terhadap potensi yang dimiliki anak dan mampu mengerti akan kebutuhan anak. ${ }^{13}$

Untuk memaksimalkan kedekatan orang tua dan anak, Direktorat Pembinaan Pendidikan Keluarga mencanangkan 4 program untuk mendukung pendidikan keluarga dirumah. Program tersebut terdiri dari (1) Pertemuan

13 Baharun,Hasan. 2016. Pendidikan Anak Dalam Keluarga;Telaah Epistemologis. Karanganyar Paiton Probolinggo. Jurnal Pendidikan, Vol. 3, No. 2 Januari-Juni 
dengan guru wali siswa; (2) kelas untuk orang tua (3) Kelas inspirasi dan (4) Pentas seni pada akhir tahun pembelajaran. Direktur pembinaan pendidikan keluarga memaparkan bahwa sejak dibentuk pada tahun 2015, Direktorat Pembinaan Pendidikan Keluarga juga memberikan layanan pendidikan keluarga di 237.332 satuan pendidikan di semua jenjang pendidikan hingga tercapai 55\% dari 429.768 jumlah satuan pendidikan yang ada di Indonesia. ${ }^{14}$

Keterlibatan orang tua dalam pendidikan anaknya di sekolah akan terlaksana dengan baik, bila telah tercipta komunikasi yang efektif antara sekolah dan orang tua siswa. Hal ini didukung dengan pernyataan dari Mendikbud dalam sebuah seminar "Pentingnya Membangun Komunikasi Efektif Orangtua-Sekolah", bahwa komunikasi antara orang tua dan sekolah akan lebih efektif bila tercipata komunikasi dua arah. Semakin sering orang tua dan wali kelas berbagi informasi yang relevan tentang peserta didik, maka semakin besar pula potensi mereka dalam membantu siswa mengatasi problem kesulitan belajar, serta menguatkan potensi yang dimiliki siswa, sehingga siswa dapat meraih prestasi, baik pada bidang akademis maupun non-akademis. Mereka juga dapat bekerja sama dalam mengubah perilaku dan kebiasaan siswa menuju yang lebih baik lagi. Peluang untuk komunikasi dua arah dapat terjadi melalui (1) Pertemuan orangtua dengan walikelas; (2) Pembentukan organisasi orangtua dan walikelas; (3) ada lembar kerja siswa mingguan atau bulanan dibawa pulang untuk diperhatikan langsung oleh orang tua; (4) Komunikasi via telepon, website atau email dan (5) home visit, (Kunjungan) ke rumah siswa.

Hal ini bertujuan untuk mempersiapkan anak-anak yang saat ini duduk dibangku SD, SMP, dan SMA dalam menghadapi berbagai tantangan di masa depan. Mengingat bahwa kelak pada 2045 Indonesia telah mencapai usia "Emas", yaitu 100 tahun kemerdekaan NKRI. Pada usia satu abad tersebut, Indonesia harus mampu mengatasi berbagai macam permasalahan. Perbaikan

\footnotetext{
${ }^{14}$ Kemendikbud Dorong Orang Tua Aktif dalam Kegiatan Sekolah (19 Oktober 2017). Diambil pada tanggal 9 April 2020. Dari https://www.kemdikbud.go.id/main/blog/2017/10/kemendikbud-dorongorang-tua-aktif-dalam-kegiatan-sekolah
} 
kualitas sumber daya manusia menjadi kunci utama dalam mewujudkan Indonesia emas 2045.

Era digital yang melaju dengan pesat membuka pertukaran informasi dan budaya tanpa ada batasan. Hal ini, membawa dampak dari segi positif dan segi negatif. Aspek positif yang didapat, seperti adanya kemudahan dalam mengakses ilmu pengetahuan, teknologi, serta informasi yang membangun. Namun, disisi lain juga terdapat dampak negatif yang menyertainya, misalnya dapat menggerus budaya dan identitas bangsa Indonesia.

Dengan demikian pendidikan keluarga sangat dibutuhkan keberadaannya dalam mencetak generasi bangsa yang memiliki intelektual tinggi, inovatif, dan kreatif, sesuai yang tertuang dalam kebijakan program Merdeka Belajar yang telah ditetapkan oleh pemerintah. Karena peranan orang tua tidak dapat tergantikan dengan teknologi yang canggih.

\section{Kerangka Konsep Pendidikan Keluarga dan Merdeka Belajar}

\section{Lingkungan}

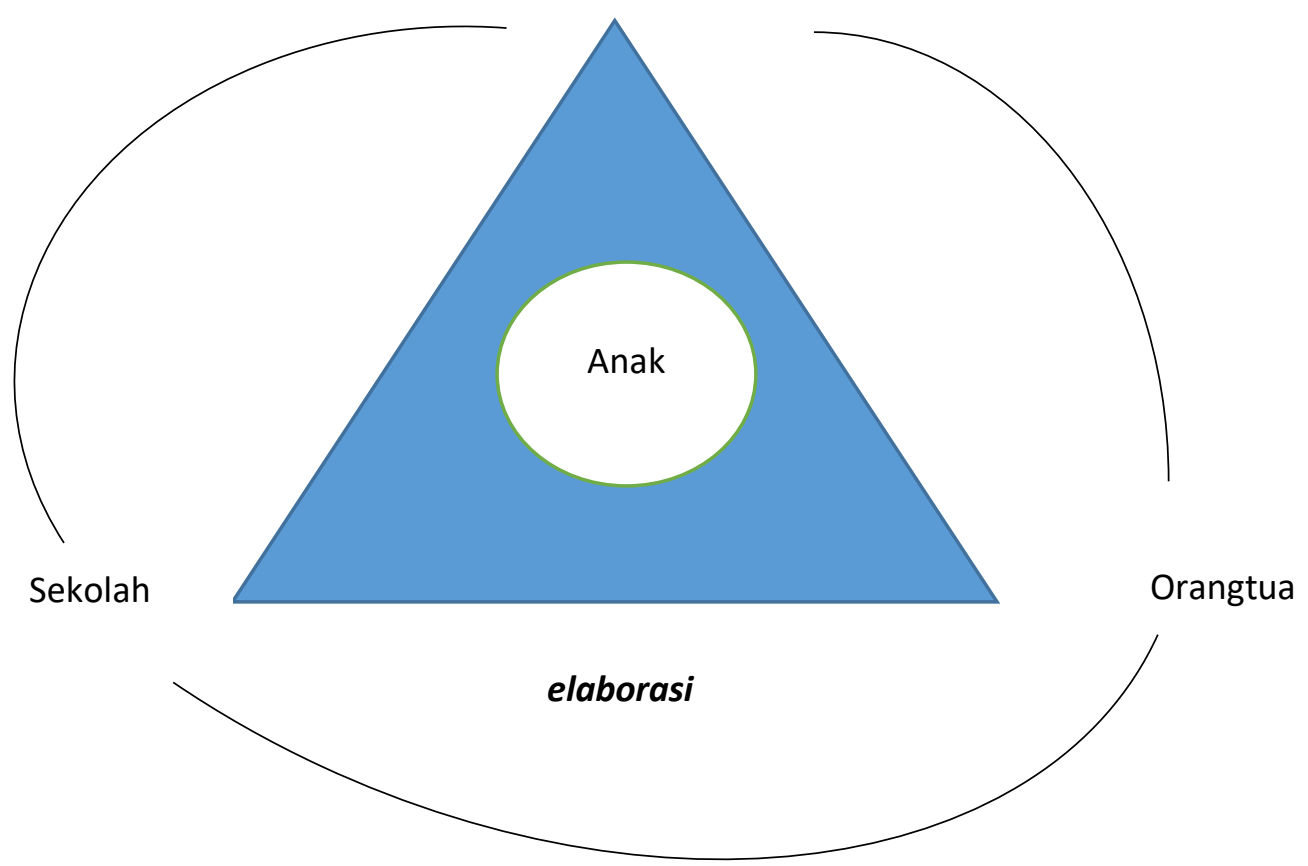




\section{KESIMPULAN}

Dari pemaparan diatas dapat disimpulkan, bahwa pendidikan dalam keluarga ialah menanamkan Keterampilan menguasai diri, Pendidikan nilai dan pendidikan sosial, pemerintah menyiapkan strategi pendidikan dengan program "Merdeka Belajar". Faktor utama yang mendukung keberhasilan program tersebut ialah adanya keterlibatan keluarga dalam lingkup pendidikan anak. Oleh karena itu, terwujudlah pendidikan keluarga yang berupaya untuk membantu siswa dalam memecahkan kesulitan belajar, memperbaiki perilaku dan kebiasaan buruk, serta memberikan penguatan pada ranah intelektual dan spiritual. Pendidikan keluarga merupakan sarana komunikasi antara wali kelas di sekolah dan wali siswa di rumah.

Dengan demikian, diharapkan adanya hubungan yang sinergi antara guru di lingkungan sekolah dan orang tua di rumah dalam menghasilkan sumber daya manusia yang mandiri, cerdas, cakap, kreatif dan inovatif, sehingga dapat bertahan dalam menghadapi berbagai tantangan dan permasalahan dimasa depan. 


\section{DAFTAR PUSTAKA}

As-Suyuthi, Jalal al-Din Mahalliy \& Jalal al-Din, Terjemah Tafsir al-Jalalain jil.3, terj.Bahrun, Bandung : Sinar Baru, 1990.

Djamarah, Syaiful Bahri, Pola Asuh Orang Tua dan Komunikasi dalam Keluarga, Jakarta: Rineka Cipta, 2014.

Helmawati, Pendidikan Keluarga: Teoritis dan Praktis, Bandung : PT Remaja Rosdakarya, 2014.

Jatnika,Yanuar. Pentingnya Membangun Komunikasi Efektif Orangtua-Sekolah (07

Agustus 2018). Diambil pada tanggal 9 April 2020. Dari

https://sahabatkeluarga.kemdikbud.go.id/laman/index.php?r=tpost/xview\&id=49

18.

Kemendikbud Dorong Orang Tua Aktif dalam Kegiatan Sekolah (19 Oktober 2017). Diambil pada tanggal 9 April 2020. Dari https://www.kemdikbud.go.id/main/blog/2017/10/kemendikbud-dorong-orang-tuaaktif-dalam-kegiatan-sekolah

Kemendikbud Dorong Orang Tua Aktif dalam Kegiatan Sekolah (19 Oktober 2017).

Diambil pada tanggal 9 April 2020. Dari

https://www.kemdikbud.go.id/main/blog/2017/10/kemendikbud-dorong-orangtua-aktif-dalam-kegiatan-sekolah.

Kemendikbud Selenggarakan Apresiasi Pendidikan Keluarga Ke-3 (26 Oktober 2018)

Diambil pada tanggal 9 April 2020. Dari

https://www.kemdikbud.go.id/main/blog/2018/10/kemendikbud-selenggarakanapresiasi-pendidikan-keluarga-ke3.

Mustaghfiroh, Siti. 2020. Konsep "Merdeka Belajar" Perspektif Aliran Progresivisme John

Dewey. Jurnal Studi Guru dan Pembelajaran, Vol. 3, No. 1, Maret.

Nurhayati, Nanik, Makalah disampaikan pada Kuliah Tamu di IAI Sunan Giri Bojonegoro 07 Maret 2019.

Suprayitno, Muhammad Padil dan Triyo, Sosiologi Pendidikan, Yogyakarta: Sukses Offset, 2007. 